\title{
LA «DESINSTANTANEIZACIÓN» DEL INSTANTE. ANÁLISIS DE LA NOCIÓN DE «INSTANTE-SITIO» \\ EN LOS BEITRÄGE ZUR PHILOSOPHIE DE MARTIN HEIDEGGER
}

\section{THE «DIS-MOMENTARINESS» OF THE MOMENT. ANALYSIS OF THE NOTION OF «SITE FOR THE MOMENT» IN MARTIN HEIDEGGER'S BEITRÄGE ZUR PHILOSOPHIE}

\author{
Ángel Enrique GARRIDO MATURANO* \\ CONICET / IIGHI, Resistencia, Argentina
}

Resumen: El artículo analiza la noción de "instante-sitio" en los Beiträge zur Philosophie a través de la reconstrucción de la noción de abismo como modo ontohistórico (seinsgeschichtlich) de acaecer del ser y de rehusamiento-itinerante (zögernde-Versagung) como espacio-temporalización del abismo. El análisis procura, en primer lugar, explicitar en qué medida la perspectiva de los Beiträge revierte la relación entre decisión y situación de Ser y tiempo a causa de la identificación del instante-sitico con la situación ontohistórica. En segundo, muestra en qué sentido la concepción extática del "instante-sitio" en el pensar del ser como Ereignis implica una des-instantaneización del fenómeno.

Palabras clave: "instante-sitio", acaecimiento, ser, espacio-tiempo, situación.

Авsтract: The article analyzes the notion of "site for the moment" in the Beiträge zur Philosophie by way of a reconstruction of the notion of abyss as a being-historical (seinsgeschichtlich) mode of the enowning of Being and of the hesitant refusal

* Profesor Dr. Ángel E. Garrido-Maturano. Investigador principal. Avenida San Martín 218, (3541) Coronel Du Graty, Argentina. hieloypuna@hotmail.com. 
(zögernde-Versagung) as the spatio-temporalization of the abyss. The analysis attempts, firstly, to explain the extent to which the Beiträge set the relationship between decision and situation of Being and Time due to the identification of the site for the moment with the being-historical situation. Second, it shows how the ecstatic view of the "site for the moment" in the thought of Being as Ereignis implies a dis-momentariness of the phenomenon.

KEYwORDS: "site for the moment", enowning, being, space-time, situation.

\section{Introducción}

Las consideraciones que aquí comienzan se ocuparán de reconstruir la noción de "instante-sitio" (Augenblick-Stätte) en los Beiträge zur Philosophie de Martin Heidegger ${ }^{1}$. Tal reconstrucción está puesta al servicio de desplegar la problemática inherente a la relación entre "instante" y situación "onto-histórica" en ésta, usualmente es considerada la obra fundamental del pensamiento heideggeriano posterior al viraje ${ }^{3}$. Pienso que el análisis de esa relación no es

${ }^{1}$ No es mucha la bibliografía dedicada específicamente al análisis del instante en el pensa-
miento heideggeriano posterior al viraje. Hasta donde mi conocimiento alcanza quisiera
señalar tres obras que me parecen particularmente significativas. Una excelente y minuciosa
reconstrucción del tema del "instante-sitio" en la obra de 1936 (aunque escrita desde una
perspectiva exclusivamente exegética) la realiza Paola L. Coriando (Coriando, 1998: 103-106
y 180-183). Otra buena exposición del tema, pero orientada a mostrar críticamente las moti-
vaciones histórico-epocales y culturales de la comprensión del presente en los Beiträge puede
leerse en Rüdiger H. Rimpler (Rimpler, 2008: 22-33). Un análisis crítico de la comprensión
heideggeriana de los temples fundamentales que hacen posible el acaecer del instante como
comienzo (y que, según el autor, mantendrían vivo el primer comienzo) ha sido en cambio la
tarea de Klaus Held (Held, 1991: $31-55$ ).
2 Con el neologismo "ontohistórico" traduzco el término heideggeriano seinsgeschichtlich, que
podría parafrasearse por la expresión "relativo a la historia destinal del ser", esto es, no a la
historia de los sucesos ocurridos en el pasado (Historie), sino a la de los sentidos fundamenta-
les (Geschichte) a través de los cuales el ser de lo que es se da a comprender a partir del modo
en que él mismo se envía o yecta en el ente para ser comprendido por el hombre. Como tal
paráfrasis no es viable estilísticamente he preferido usar el término "onto-histórico". Si se
entiende "ontos" no en sentido nominal, sino verbal como aquello que le da su ser esencial a
la historia, la traducción, aunque imperfecta, puede justificarse.
3 Por "viraje" ("Kehre") debe entenderse aquí el paso del pensamiento heideggeriano de la
pregunta por el sentido del ser, formulada desde la perspectiva de la comprensión horizontal-
trascendental del ser del ente propia del Dasein, que impera fundamentalmente en Ser y
tiempo, a la misma pregunta por el sentido del ser, pero desplegada ahora desde el
acaecimiento ontohistórico del ser, es decir, desde la verdad del ser que no es otra que acaecer
históricamente fundando un modo esencial de comprensión de lo que es en su conjunto. En 
un tema menor, en la medida en que re-determina la comprensión del instante como "instante-sitio"; y en la medida también en que el "instante-sitio" constituye, para Heidegger, la modalidad en la que se congrega y despliega la espacio-temporalización originaria del ser como acaecimiento.

Dentro del marco temático señalado el presente artículo persigue dos objetivos. Primero mostrar por qué en la comprensión del "instante-sitio" de los Beiträge se produce una inversión de las relaciones de prioridad entre decisión y situación respecto al modo en que estas relaciones se desplegaban en el marco de Ser y tiempo. En este sentido, parto de la hipótesis de que dicha inversión resulta una consecuencia inevitable de la equiparación de la originariedad y esencialidad de espacio y tiempo en la obra de 1936, como así también del primado en ella de una concepción pasivo-responsorial del fenómeno del instante. En segundo lugar, el análisis se propone mostrar que la comprensión del fenómeno en el marco de la correspondencia de la espaciotemporalización de la existencia con la espacio-temporalización del acaecer del ser en su verdad como abismo produce lo que podría caracterizarse como una "des-instantaneización" del instante, en la medida en que el carácter extático de tales espacio-temporalizaciones diluye y termina excluyendo la idea de instante como acontecimiento singular, repentino y puntual, que altera desde fuera del horizonte de la correlación tanto el curso de la historia del ser como el de la existencia que en ella se desarrolla.

El método que aquí aplicaremos es fundamentalmente hermenéutico. Unas breves aclaraciones no serán del todo superfluas para evitar malentendidos. La primera de ellas es de índole negativa y se refiere al tipo de interpretación que aquí no desplegaremos. Mi interpretación se aparta intencionalmente de aquella otra perspectiva hermenéutica que podríamos calificar como "exégesis interna". Ella consiste en re-exponer un cierto texto desplegando el conjunto de implicaciones interrelacionadas y matices significativos que se hallarían densamente condensados en su interior, pero de modo tal que lo que rige dicho despliegue no es sino poner de manifiesto precisamente la densidad significativa de lo que el autor mismo dice desde la perspectiva en que lo dice. No es mi intención cuestionar la legitimidad de esta metodología, sólo puntualizar que

otros términos, el viraje puede explicitarse como un paso del Da-sein, es decir, del ser del existente que pro-yecta un "ahí" en que el ser (sentido) de lo ente puede manifestarse, al Da-sein, esto es, a la yección de un determinado "ahî" $(D a)$ en el que el ser mismo se yecta o abre y para que el hombre pueda, a partir de su yección, proyectar el ser de todo aquello en relación con lo cual es, de sí mismo y de su propia existencia. 
no es ella ni, consecuentemente, el intento de realizar una exégesis exhaustiva del concepto de instante en la obra heideggeriana aquella dirección que guiará la reconstrucción que hagamos de nuestro tema. La segunda aclaración metodológica es de índole positiva y se refiere al tipo de interpretación a desplegar y que podría ser entendida como el intento de llevar adelante una "apropiación significativo-crítica" del texto. Por "apropiación significativa" entiendo elucidar el significado que tienen los aspectos fundamentales de la comprensión heideggeriana del instante como "instante-sitio" para mi propia problemática, a saber, para determinar en qué medida puede ser comprendido adecuadamente el instante como un fenómeno esencialmente extático y en qué medida también se puede dar cuenta de él desde una situación ontohistórica sin diluir su "instantaneidad" en el constante despliegue de los horizontes extáticos de la historia del ser. En tanto crítica, la apropiación no quiere señalar presuntas "fallas" en la exposición de Heidegger, sino precisar en qué medida su concepción y las presuposiciones que le son inherentes no alcanzan a dar cuenta desde sí de lo propiamente instantáneo del instante.

Para reconstruir el sentido que Heidegger le otorga al "instante-sitio" en su filosofía posterior al viraje es menester referenciar en qué medida el análisis del fenómeno en el $\$ 242$ de los Beiträge no es un mero "cambio inmanente" (Falkenhayn, 2003: 216) o un decir de otro modo lo ya dicho en Ser y tiempo respecto del "instante" como presente de la existencia auténtica, sino una inversión que implica una verdadera reversión de los análisis desarrollados en la obra maestra de 1927. Por lo tanto, comenzaremos recordando muy sintéticamente los trazos esenciales de la comprensión del instante en aquella obra.

\section{Instante y situación en el contexto de Ser y tiempo}

En Ser y tiempo Heidegger introduce el concepto de instante en el contexto del análisis de los éxtasis a través de los cuales el existente temporaliza su comprender propio. Si el comprender es ser en función de la proyección de posibilidades, el comprender propio es el de aquel Dasein que se proyecta en función de sus posibilidades más propias. Y la posibilidad más propia del Dasein es el "ser relativamente a su muerte". La muerte es la posibilidad

\footnotetext{
${ }^{4}$ Concuerdo con la estudiosa en que los análisis de los Beiträge no dan por falsos los de Sein und Zeit, sin embargo entre ambos hay diferencias conceptuales fundamentales que no se pueden reducir a un cambio referido al lugar "desde donde es planteada la pregunta por el ser" (2003: 216).
} 
más propia de cada Dasein, porque ella es, por antonomasia, la posibilidad irreferente, irrebasable, cierta, pero indeterminada del existir. Como posibilidad irreferente, la muerte me singulariza en mi más propio ser, pues mi muerte es sólo mía. En cuanto irrebasable, es también mi posibilidad más propia, pues no puedo ir más allá y en ella desembocan y se totalizan el conjunto de posibilidades a través de las cuales despliego mi existencia. En tanto cierta, es la más propiamente posible de todas. Finalmente, en tanto indeterminada y siempre inminente, la muerte es de nuevo la posibilidad más propia, pues es constantemente posible. Existir propiamente, es decir, existir de acuerdo con lo que originariamente somos, a saber, seres ya siempre referidos a su propia muerte, significará, consecuentemente, proyectar a cada instante el conjunto de nuestras posibilidades sobre el trasfondo de la posibilidad de la muerte. A tal modo de ser, lo denomina Heidegger "precursar" (Vorlaufen). En consecuencia, el modo auténtico de proyectase y advenir a sí mismo es el "precursar". Pero todo advenir no lo es desde la nada, sino desde lo que hemos sido. Por lo tanto todo "precursar" o advenir propio lleva en sí un sido o pasado propio. A éste lo llama Heidegger, retomando un término de Kierkegaard, re-iteración (Wiederholung). Sólo puedo ser relativamente a mi muerte del modo en que a mí me es propio proyectarla si re-itero, es decir, recupero y vuelvo a recorrer, en mi camino a la muerte las posibilidades que ya he sido. Pues bien, el instante es el modo en que acontece el presente en el comprender del existente que temporaliza el conjunto de su existencia como “precursar-reiterante”. ¿Qué significa concretamente concebir este presente propio como instante? $\mathrm{Al}$ respecto escribe Heidegger: "Al precursar del estado de resuelto le pertenece un presente según el cual una resolución abre la situación” (1993: 338). Si tenemos en cuenta esta aserción, observamos que el presente del estado de resuelto -el instante- está referido a existir en una situación. La situación la define Heidegger en los siguientes términos: "La determinación existenciaria del respectivamente posible ser resuelto del ser ahí abarca los momentos constitutivos de aquel fenómeno existenciario pasado por alto hasta aquí que llamamos la situación" (1993: 299). La definición, en última instancia, refiere la situación al conjunto finito de posibilidades que conciernen a un Dasein y que, por tanto, son respectivas a él. Es en función de estas posibilidades, que emergen del sido del existente del caso y que lo proyectan de un cierto modo hacia su posibilidad última, que se configura la situación. En conclusión, el instante es aquel presente extático del estado de resuelto que se temporaliza en unidad con la reiteración y el "precursar" y gracias al cual se abre o descubre para el existente su situación respectiva. 
Ahora bien, no es la situación la que abre el instante, sino, como vimos, es el presente propio de la resolución -el instante- el que abre la situación. ¿Por qué? El instante es aquel presente en el que el existente, manteniendo reunidos el conjunto de sus éxtasis temporales, echa una mirada al mundo en el que es. Entonces advierte "aquello que de posibilidades y circunstancias susceptibles de que se ocupe encuentra en la situación." (Heidegger, 1993: 338). Dicho de otro modo, sólo gracias al vistazo o mirada (Augen-blick) que ocurre en el instante en que me decido a "precursar" la muerte desde la reiteración de mis posibilidades sidas se abre la situación con sus posibilidades fácticas respectivas. Así vistas las cosas, el instante es el presente extático de la resolución que abre el espacio de la situación. En efecto, la condición de la apertura de la situación es la resolución, pues toda vez que la resolución acontece como mirada (de hecho no sin razón Gaos traduce Augenblick por mirada y no por instante) que se prolonga extáticamente hacia mis horizontes temporales se configura la situación. En síntesis, en el marco de Ser y tiempo es la decisión o resolución de existir propiamente quien abre nuestro respectivo espacio situacional. En tanto la decisión o resolución ocurre como un modo de temporalizar el presente de la existencia, en el instante prima el tiempo sobre el espacio. En tanto la decisión resulta de un modo de relacionarse con y asumir mi propia existencia, el instante es la expresión de la más auténtica actividad del Dasein: su resolución. Ambos aspectos, esenciales en Ser y tiempo, se invertirán en los Beiträge zur Philosophie.

\section{La noción de "instante-sitio" en el contexto de los Beiträge zur Philosophie}

\subsection{El abismo}

Todo intento de explicitar el sentido de una cierta noción de los Beiträge zur Philosophie debe primero tener en cuenta que la pregunta fundamental que constituye el horizonte último de los distintos "ensambles" (Fügungen) del libro sigue siendo, como en Sein und Zeit, la pregunta por el sentido del ser en general. Sólo que en los Beiträge se produce un "viraje" del pensamiento, que ahora formula la pregunta por el sentido del ser no desde la comprensión del ser del existente en tanto Dasein, sino desde el acaecimiento (Ereignis) ${ }^{5}$ del

\footnotetext{
${ }^{5}$ La palabra Ereignis en el alemán corriente significa acontecimiento. En ella, sin embargo, se distinguen, desde el punto de vista morfológico, el prefijo "er", que indica actividad procesual y transitiva, y "eignis" que podríamos traducir por apropiación, en el doble sentido de, por un
} 
ser mismo. Pensar la pregunta por el sentido del ser desde el ser concebido como acaecimiento significa hacerlo desde el modo en que él en su verdad, es decir, en tanto ser (sin reducir su sentido a la entidad del ente) se yecta históricamente en el todo del ente. Se trata, pues, de pensar, la pregunta por el ser desde la historia del acaecer del ser en su verdad como ser, desde la mismísima "verdad del ser". Desde este punto de vista el viraje hacia el pensar del ser como acaecimiento es, en primer lugar, un viraje hacia el pensar del ser como acaecimiento "ontohistórico". Ahora bien, el acaecer o yección histórica del ser como ser en el todo del ente se des-oculta y se vuelve, así, verdad (a-letheia), sí y sólo si ella se apropia del modo en que el existente pro-yecta su existencia y el sentido del ser del ente en su conjunto, de modo tal que su existir mismo devenga el ahí $(D a)$ en el que el ser (sein) acontece y se manifiesta. Desde este otro punto de vista el viraje hacia el pensar del ser como acaecimiento es también un viraje hacia el pensar del ser como acaecimiento apropiador. En tal acaecimiento pueden, pues, distinguirse propedéuticamente dos aspectos que se dan conjuntamente. Por un lado la apropiación de la yección ontohistórica del $\operatorname{ser}^{6}$ en el ente por el Dasein, concretamente por el modo en que éste proyecta su existencia en el horizonte del mundo. De allí que todo proyecto del Dasein -toda comprensión fundamental tanto de su existir como del sentido del conjunto de los entes que le salen al encuentro- sea un proyecto acaecido, precisamente porque resulta de apropiarse de una yección previa -ya acaecida- del ser en el ente. Por otro lado, la yección ontohistórica del

lado, apropiarse de algo, esto es, hacerlo propio de y perteneciente a uno, y, por otro, de alcanzar, así, la propiedad y autenticidad del propio ser. Todos estos matices están presentes en el uso heideggeriano del término, pues el Ereignis es un acontecimiento procesual, histórico y transitivo que vincula la esencia del hombre y la del ser; y en virtud del cual ser y hombre se apropian uno de otro y alcanzan, así, ambos su esencia más propia. El ser alcanza su esencia como acontecer del sentido fundamental del todo del ente a través de la comprensión proyectada por el hombre del sentido de todo lo que es a partir precisamente del acaecer del ser. Y el hombre alcanza correlativamente su esencia de Da-sein, de lugar y momento a través del cual el ser desoculta su acaecer en el ente en su conjunto. Ninguna de las traducciones factibles en español reúne todos estos matices semánticos. En este artículo traduciré el término por "acaecimiento" para destacar el hecho de que el ser no es algo (ente), sino que su verdad radica meramente en acaecer y, haciéndolo, hacer que el conjunto del ente se manifieste de un cierto modo.

${ }^{6}$ Por yección (Zuwurf) del ser debe entender el lector no especializado en la terminología de los Beiträge una suerte de posibilidad de sentido incipiente o latente que resulta del modo en que se encuentran entre sí y le salen al encuentro a un determinado Dasein el conjunto de los entes con los que éste se relaciona. Este sentido latente interpela o llama al existente para que se lo apropie, comprenda y lo articule en un mundo, de modo tal de poder acaecer efectiva e históricamente como tal. 
ser en el todo del ente se apropia de la proyección ${ }^{7}$ que hace el Dasein de su existir en el mundo para que éste la articule y haga que efectivamente pueda concretarse. De allí que toda yección ontohistórica del ser sea siempre una yección acaeciente, es decir, que tiene que ser apropiada por el proyecto fundamental de un Dasein para ser llevada al acaecer efectivo. En síntesis, los Beiträge deben entenderse desde el horizonte de la pregunta por el ser, pero formulada a partir de del acaecimiento ontohistórico y apropiador del ser en su verdad. ¿Y cuál es, pues, el sentido originario del acaecer ontohistórico y apropiador del ser en su verdad? ¿Cómo ha fundado desde los orígenes mismos de la historia el acaecer del ser el modo en que el existente en tanto Da-sein comprende el ser del ente?

Para Heidegger el ser acaece originariamente como abismo $(\text { Ab-grund })^{8}$. "El abismo es la originaria esenciación (Wesung) $)^{9}$ del fundamento." (Heidegger, 1989: 379). ¿Y cuál es el modo de fundar (nuestra comprensión del ser del ente) del ser como abismo? Heidegger caracteriza este fundar como un mantenerse apartado (Wegbleiben) y estar ausente (Ausbleiben) del fundamento.

\footnotetext{
${ }^{7}$ Por proyección (Entwurf) debe leer nuevamente el lector no del todo familiarizado con la obra que estamos analizando, precisamente aquella comprensión del sentido de su existir y del todo del mundo en el cual existe a través de la cual el existente se apropia del sentido implícito que lo "llama" desde el conjunto de lo que es. Proyecto tiene aquí el mismo sentido que en Ser y tiempo, sólo que en el horizonte de los Beiträge no se funda en la espontaneidad trascendental del existente, sino en la yección del ser. Por ello mismo es acaecido.

${ }^{8}$ El término "Abgrund" significa en el alemán corriente "abismo", esto es, lo que se precipita (ab) hasta el fondo o suelo (Grund) último. Etimológicamente se compone de "Grund" que significa precisamente la tierra en tanto "suelo" o "piso" y, por tanto, extensivamente, "fundamento", y del prefijo " $a b$ ". " $A b$ " proviene, en última instancia, del indogermano *apo, del que se derivan tanto el griego " $a p o$ ", que significa "de" o "desde", como el latino "ab", que significa "sin" o "privado de". Todos estos matices están presentes en el uso heideggeriano del término abismo que es concebido como aquel especial modo de fundar que proviene desde el ser mismo en tanto fundamento, pero que consiste en el retraerse del ser y dejar sin o privado de su relación con el fundamento a lo fundado: la comprensión del ser del ente.

9 Traduzco el neologismo alemán "Wesung" por el español "esenciación”. Heidegger utiliza "Wesung" en lugar de "Wesen" (esencia) para resaltar que no comprende la esencia del ente en un sentido fundamentalmente nominal, sino verbal, en la medida en que la esencia del ente resulta del modo de acaecer del ser. El sentido nominal sería precisamente el que se ve reflejado en el sustantivo "Wesen", que tradicionalmente en alemán ha servido para traducir el latino "essentia". Con Wesen se mentaba la esencia de lo que es desde la ontología de la sustancia: como aquello que el ente del caso, atemporalmente pensado, es en sí y por sí mismo. Wesung, por el contrario, es un modo diferente de sustantivar el verbo "wesen", que usualmente significa ser, pero ser de un modo esencial. Con Wesung quiere indicar Heidegger que la esencia del ente resultaría de la "esenciación" esto es del modo en que acaece esencialmente y se temporaliza el ser en él. Así concebida, como esenciación la esencia es fundamentalmente verbal.
} 
"El Ab-ismo es el mantenerse apartado del fundamento." (Heidegger, 1989: 379). De acuerdo con ello, el ser desde los orígenes ontohistóricos de su yección en el todo del ente se retrae como ser para dejar surgir la entidad del ente. Ahora bien, esa retracción implica que el hombre "olvide" que al ente le es dada su entidad y su sentido por el modo en que el ser acaece en el conjunto de lo que es ${ }^{10}$. Consecuentemente el hombre piensa que en sí mismo el ente no recibe ningún sentido, sino que su sentido le puede ser adjudicado arbitrariamente por él mismo. Este proceso -que todo lector de Heidegger conoce suficientemente y en el no ahondaré- de vaciamiento del sentido del ser del ente es característico de la modernidad, en la que el Dasein se comprende a sí mismo como sujeto capaz de determinar a través de la ciencia natural el ser del ente reducido a objetividad. Cuando se llega a este punto, impera la convicción de que el ente por sí mismo no está dotado de sentido o, dicho en otros términos, de que su ser no se funda en nada. Desde este momento el ser del ente se identifica con una nada susceptible de recibir el sentido que el hombre arbitrariamente determine. La última expresión de esta reducción nihilista del ser del ente es su reducción a instrumento utilizable a voluntad por el hombre a través de la técnica. Sin embargo, el fundamento último de esta situación histórica no es otro que la retracción (Entzug) del ser que se retira como fundamento hacia el abismo y deja al ente privado de aquello que ha fundado su ser-ente. No es que como abismo el ser deje de ser fundamento, sino que sigue fundando, pero en el modo negativo de mantenerse apartado como fundamento del ser del ente.

Desde el punto de vista ontohistórico el fundar del ser en el modo del abismo (a diferencia del fundar en sentido propio, a saber, aquel fundar en el que el ser se hiciera patente como fundamento de cada posible sentido del ente) representa para Heidegger el modo inicial (anfänglich) del fundamento. A este modo inicial no le sigue ningún segundo modo de fundar, puesto que él ha imperado desde el inicio del pensamiento occidental y ha hecho posible la entera historia de la metafísica, concebida precisamente como determinación

\footnotetext{
${ }^{10}$ Considero necesario, desde mi interpretación fenomenológica, alejar toda lectura "mística" que tienda a identificar el ser con una suerte de Deus ex machina que le da su ser al ente. El ser no mienta ninguna entidad sobrenatural, pues no mienta ninguna entidad en absoluto. Por el contrario, el ser refiere el modo en que el ente acaece en el conjunto de correlaciones que sostiene con los otros entes dentro del horizonte o mundo en el cual se da y, consecuentemente, el sentido que emerge a través de ese acaecimiento. El ser mienta, pues el acaecer de un cierto encuentro en el ente de todas las regiones que componen el mundo en tanto horizonte (y que Heidegger identifica con la cuaternidad) y del que emerge un sentido a través de ese ente.
} 
de la entidad del ente a partir del olvido del ser retraído al abismo. La idea del primer comienzo refiere justamente la posibilidad ontohistórica de que haya otro comienza en el que el ser funde, pero no a partir de su retracción, sino a partir de su arribo (Anfall) como fundamento en el sentido propio. Mas la precondición para que sea posible otro comienzo es mantener presente que el abismo es el modo inicial en que el ser ha fundado el sentido del ente. De lo contrario, si no experimentamos la retracción como tal, si olvidamos que hemos olvidado el ser como fundamento del ser del ente, entonces la posibilidad de otro comienzo se perdería por completo. Ahora bien, tener presente que el ser ontohistóricamente funda como abismo equivale a tener presente cómo acaece el abismo en tanto mantenerse apartado del fundamento. Para Heidegger el abismo en tanto primera esenciación (Wesung) del fundamento resulta, como todo acaecimiento, de un modo de espaciación y temporalización. Escribe Heidegger: "El abismo como primera esenciación del fundamento funda (deja al fundamento ser esencialmente fundamento) en el modo de la temporalización y la espaciación" (1989: 383). Esa espacio-temporalización originaria y fundante es concebida como el ensamble resultante de un triple desplazamiento (Entrückung) temporal y un emplazamiento (Berückung) espacial de carácter extático dentro del cual cobrará su auténtico sentido el "instante-sitio."

\subsection{El rehusarse itinerante}

Escribe Heidegger en el célebre $₫ 242$ de los Beiträge: "La verdad como fundamento funda sin embargo originariamente como abismo. $Y$ éste funda como la unidad de temporalización y espaciación" (1989: 383). Esa unidad originaria de espaciación-temporalización desde la que emergen tiempo y espacio en su diferenciación resulta del acaecer abismal del ser como "rehusamiento itinerante" (zögernde ${ }^{11}$ Versagung). Más específicamente: el "rehusarse" mienta la temporalización originaria del acaecer del ser como abismo; y el "itinerar" su espaciación originaria, que se da conjuntamente con

\footnotetext{
${ }^{11}$ Zögernd es el participio presente del verbo zögern que significa usualmente "titubear", "vacilar" y, por tanto, "demorarse" o "retrasarse" en la toma de una decisión. Zögern proviene del verbo zogōn que en antiguo alto alemán significa llevar algo de un lado para otro y que se emparenta con el verbo ziehen ("tirar", "mover de un lado hacia otro"). Originariamente significa, pues, mover reiteradamente de un lado a otro. Por ello mismo puede traducirse zögernd por "itinerante", en tanto en cuanto el rehusamiento como modo de temporalización del abismo se espacia yendo una y otra vez a lo largo del tiempo de un ente en otro y configurando, así, el espacio mismo del ente (cf. Drosdowski, 1989: 833).
} 
el rehusamiento. Centrémonos primero en el rehusamiento. Éste presenta una estructura extática que se temporaliza a través de tres éxtasis co-originarios que Heidegger denomina "desplazamientos". En su triple desplazarse el rehusamiento temporaliza el vacío que deja el ser cuando acaece retrayéndose y funda en el modo del abismo. De él afirma Heidegger:

El rehusarse genera [...] el vacío como un vacío en sí mismo desplazante, a saber, uno tal que se desplaza hacia el advenir (Künftigkeit) y que con ello a la vez entreabre un sido que permanece siendo (Gewesendes), el cual, topándose con lo adviniente, configura el presente como desplazamiento en el abandono [del ser A G-M], pero como un abandono que recuerda y se mantiene a la espera (1989: 383).

En el texto precedente Heidegger dirige la vista al modo en que se temporaliza extáticamente la comprensión del ser del Dasein cuando el ser del ente es fundado por el acaecimiento ontohistórico del ser en su verdad como abismo. Ese temporalización articula el tiempo abismal en un triple desplazamiento extático. En primer lugar, encontramos el desplazamiento en el advenir (Künftigkeit). Este desplazamiento es concebido por Heidegger como un modo extático de encontrarse el Dasein ya siempre avanzando o protendiendo hacia lo que adviene. Se trata de un modo de pro-tender, es decir de proyectarse hacia lo que adviene que consiste en mantenerse a la espera (erharren) de un llamado (Zuruf) del ser (ahora retraído). Sólo cuando este llamado ocurra y el Dasein se lo apropie y lo proyecte en el modo en que él comprende el ser de los entes podrá el ser fundar manifiestamente el sentido del ente. En segundo lugar, encontramos el desplazamiento en lo ya sido que aún hoy perdura y continúa siendo. A esto "sido que sigue siendo" lo llama Heidegger "Gewesendes", utilizando un neologismo construido sobre la base de la substantivación de la raíz del participio pasado (gewesen) del verbo ser (sein) pero con la desinencia del participio presente (seiend). El neologismo intenta, así, resaltar la imbricación extática de ambas dimensiones temporales. Este segundo desplazamiento es concebido por el filósofo como aquel modo extático de encontrase el Dasein ya siempre regresando o retro-tendiendo hacia lo "sido que sigue siendo". Se trata de un modo de retro-tender, es decir de recuperar lo sido que sigue siendo, que consiste en recordar (erinnern) la pertenencia (Zugehörigkeit) del Dasein al acaecer del ser, en la medida en que él es el ahí en que el ser se manifiesta. Y finalmente el desplazamiento extático en el presente (Gegenwart), concebido como el permanecer en el presente el Dasein man-teniendo la experiencia (erfahren) del abandono del ser (Seinsverlassenheit) 
como fundamento del ser del ente. Esta experiencia del abandono del ser en tanto desplazamiento extático es una experiencia que ya siempre está a la espera (erharrend) de que el ser de algún modo llame, para que el Dasein proyecte su comprensión del ser del ente a partir de este nuevo llamado; y también una que recuerda (erinnernd) la pertenencia esencial del Dasein al desocultamiento del ser. Por ello mismo ella no es un mero "hundirse" en el abandono del ser para permanecer en él, sino "el presente erigido y dirigido sólo hacia la decisión: 'instante' (Augenblick)” (Heidegger, 1989: 384). El filósofo introduce aquí, enfocado exclusivamente en su aspecto temporal, la noción de instante. El instante, así considerado, no es un punto del tiempo, sino la reunión extática de las dimensiones de la temporalización del acaecer del ser como abismo, en tanto él se encuentran el horizonte de futuro de un posible (pero epocalmente esquivo) llamado del ser y el vasto horizonte pasado de la originaria (pero históricamente no asumida) pertenencia del hombre al ser. Por ello puede decir Heidegger que los desplazamientos se desplazan hacia el instante "y él mismo en su esencia es sólo como la congregación (Sammlung) de los desplazamientos" (1989: 384).

De este modo se disgrega (hacia el futuro llamado del ser y el seguir siendo de la pertenencia al ser) y se congrega (en el instante de la experiencia del abandono del ser) el todo estructural de la triple temporalización ${ }^{12}$ extática del acaecer del ser como abismo. Este triple desplazamiento, pensado a partir de la yección ontohistórica rehusante del ser mismo, no es otra cosa que la temporalización del tiempo originario como horizonte sobre la base del cual el Dasein temporaliza su existencia propia y su relación con el ser de los entes que le hacen frente en el mundo. En tanto en cuanto esta temporalización experimenta como tal los horizontes temporales de la yección retractiva del ser como abismo en vez de sumirse en el presente del absoluto olvido y abandono del ser como fundamento ella se convierte en la temporalización del instante de la posibilidad de un otro comienzo.

\footnotetext{
${ }^{12}$ Por temporalización entendemos aquí el fenómeno extático del acaecer del ser en tanto este acaecer se da en el horizonte de tres dimensiones temporales interpenetradas: el advenidero llamado del ser, la pertenencia al ser, que es lo ya siempre sido que sigue siendo, y el presente abandono del ser como fundamento del sentido del ente. El modo en que el Dasein temporaliza su existencia, es decir, el modo en que experimenta el decurso temporal de su existir y lo dimensiona en los horizontes de pasado, presente y futuro debe ser visto es en el horizonte de los Beiträge como una respuesta al modo en que se temporaliza el ser mismo. Sobre las diferencias entre las nociones de tiempo y temporalidad -un tema ciertamente arduo en el que no puedo entrar aquí- puede consultarse mi libro Los tiempos del tiempo (cf. GarridoMaturano, 2010: 212-233).
} 
Desde un punto de vista estructural, la temporalización es inescindible de la espaciación del acaecer del $\operatorname{ser}^{13}$, pues el abismo, como todo acaecimiento, se da espacio-temporalmente. Esto puede expresarse en el peculiar lenguaje de los Beiträge recordando que todo rehusamiento del acaecer abismal del ser es itinerante (zögernde Versagung). ¿Cuál es, pues, la espaciación originaria del espacio-tiempo que se corresponde con su temporalización como triple encontrase desplazado a la espera del llamado del ser, al recuerdo de la pertenencia al ser y la experiencia del abandono del ser? Escribe Heidegger: "El rehusarse $[. .$.$] como itinerante es a la vez el más originario emplazamiento { }^{14}$. Este emplazamiento es la contención (Umhalt), en la que el instante y con él la temporalización se mantienen" (1989: 384). El rehusarse, en tanto itinerante, esto es, en tanto lleva al triplemente desplazante rehusamiento aquí y allí, emplaza el rehusamiento siempre en un espacio en el cual se asienta. El neologismo Um-halt (literalmente lo que se tiene en torno y que propongo traducir por "con-tención") con el que Heidegger determina el emplazamiento equivale a la congregación (Sammlung) en la que el instante temporal reúne los otros desplazamientos en el presente. En la contención se fija en una cierta situación, que legítimamente podría interpretarse como la presencia articulada de un ámbito espacial de concernencia, el triple desplazamiento temporalizante del rehusamiento del ser. En aquel emplazamiento, que contiene congregado en la experiencia presente del olvido del ser el triple desplazamiento temporalextático del tiempo originario, se le concede un espacio o sitio (Stätte) a un nuevo modo de acaecer del ser, pues sólo sobre la base de la experiencia situada del olvido del ser puede éste salir de su olvido. En este espacio o sitio se mantiene, pues, viva la posibilidad del acaecimiento de una nueva donación del ser que se apropie del Dasein y funde, a través de la comprensión del ser inherente a éste, un nuevo sentido del ente. Por ello la cita anterior puede

\footnotetext{
${ }^{13}$ En esencia el término "espaciación", que debe pensarse conjuntamente con "temporalización", mienta, dicho simplemente, el modo en que el ser se me "acerca”, esto es, el ámbito u horizonte espacial de concernencia o atingencia en el que estoy arrojado en función del modo en que me salen al encuentro el conjunto de los entes. Dicho ámbito pugna por ser proyectado y articulado como situación por el existente. Precisamente el modo en que Heidegger concibe el espacio en Ser y tiempo, esto es, como "desalejamiento", debe ser concebido como la articulación en una situación de esa espaciación originaria del ser. La diferencia -no menor por cierto- radica en que en el horizonte de los Beiträge la "espaciación" no es, como en Ser y tiempo, un fenómeno derivado de la temporalización, sino cooriginario con ella.

${ }^{14}$ Por "emplazamiento" traduzco el término alemán "Berückung". Así como los "desplazamientos" ("Entrückungen") mientan los modos extáticos en que el ser dimensiona su acaecer temporal, los emplazamientos mientan los modos extáticos y dinámicos en que cooriginariamente el ser sitúa en un ámbito espacial de concernencia (situación) su acaecer temporal.
} 
proseguir así: "El emplazamiento concede la posibilidad de la donación esenciante, la espacia. El emplazamiento es la espaciación del acaecimiento" (1989: 384). Es precisamente este emplazamiento, que contiene el triple desplazamiento extático de la temporalización del ser en su verdad, quien sitúa y concreta el instante de la experiencia del abandono del ser, otorgándole, así, a esta experiencia la plenitud de su significación. En este sentido continúa Heidegger: "El abandono del ser es a través del emplazamiento uno asentado (festgestellt) y dado a soportar (auszustehende)" (1989: 384). En efecto, el emplazamiento le otorga a la experiencia del abandono del ser un sitio en el que dicho abandono queda asentado y, consecuentemente, una situación en la que el Dasein habrá de so-portarlo y re-sistirlo. El emplazamiento, así concebido, como sitio que asienta la situación donde so-portar el abandono del ser, completa el instante de la congregación de los desplazamientos temporales en el presente y lo convierte en el "instante-sitio" en el que dicha experiencia es fijada y soportada, y desde el cual el Dasein se decide a mantenerse a la espera de un nuevo advenimiento del ser, preparando, de ese modo, la posibilidad de tal advenimiento.

La noción de "instante-sitio" mienta la unidad originaria y, por tanto, la co-originariedad de espacio y tiempo en el contexto del pensamiento heideggeriano del Ereignis. Esta igual originariedad puede expresarse también afirmando que no sólo el espaciarse del acaecer del ser funda el sitio del instante, sino que concomitante el temporalizarse funda el instante del sitio. Dicho de otro modo, el sitio se abre como el ámbito en que se emplaza y que contiene la posibilidad del advenimiento del ser como fundamento del ser del ente, si y solo sí el instante lo hace allí mismo como el presente que congrega los desplazamientos temporales y, de ese modo, nos coloca en condición de decidir si sí o si no seguimos haciendo posible dicha posibilidad de advenimiento. El instante de decisión no se dirige a cualquier lugar, sino a aquel sitio en que se da la posibilidad de decidir. Correlativamente el sitio de la posibilidad no nos sale al encuentro como tal en cualquier momento, sino en el instante en que estamos en condiciones de tomar una decisión respecto del hacer posible la posibilidad del advenimiento del ser. Sin un instante en que pudiéramos dirigirnos hacia un posible advenimiento del ser no habría sitio posible para tal advenimiento y sin la posibilidad de un advenimiento no sería posible decisión alguna. Por ello mismo, porque el sitio no es tal sin el instante y el instante no lo es sin el sitio, podemos decir que el instante es ya siempre instante del sitio y el sitio sitio del instante. Por ello también puede afirmar Heidegger que "el espacio-tiempo como la unidad de la temporalización y 
espaciación originaria es originariamente el mismo instante-sitio" (1989: 384).

De este "instante-sitio" nos dice el filósofo de Messkirch que es "la abismal espacio-temporalidad relativa a la esencia de la patencia del ocultamiento, es decir, del ahî" (1989: 384). La expresión "patencia del ocultamiento" podría ser reformulada como el mostrarse el ser como lo que se retrae en tanto fundamento del ser del ente para hacerlo como abismo. El ser mismo como abismo es lo patente en esta patencia. Sin embargo, lo oculto en cuanto oculto deviene patente no en sí mismo, sino en la medida en que el existente proyecta en su existir la experiencia del encontrarse yecto en una situación determinada por el abandono del ser. Ahora bien, el hombre experimenta como tal el abandono del ser en el instante presente en que se decide a mantenerse a la espera de un nuevo arribo del ser y en el sitio que contiene y abre la posibilidad de tomar una decisión tal. De allí que el "instante-sitio" como modo de espacio-temporalización de la existencia del Dasein devenga el "ahí" de la patencia del ocultamiento del ser. En consecuencia el "instante-sitio", antes que un acontecimiento de algo en un tiempo y espacio determinados, debe ser pensado como un modo de existencia, precisamente aquel que espaciotemporaliza un "ahî" en el que el ser pueda manifestarse en su retracción y, así, mantenerse viva la posibilidad de decidir en pro de un (posible) nuevo arribo suyo. Desde este eventual arribo el hombre podría repensar íntegramente el sentido del ente y nuestra relación con él. Como sintetiza Paola Coriando, "el instante es ontohistóricamente pensado siempre el instante-sitio de la tornante decisión, a través de la cual la re-tracción (Ent-zug) [del ser] se torna re-ferencia (Be-zug) [al ser]" (1998: 180).

\section{Instante y situación}

Coriando comienza su análisis de la relación entre el "instante-sitio" y el ahí $(D a)$ constitutivo del Da-sein abstrayendo metodológicamente el sitio y considerando el fenómeno exclusivamente en su aspecto de "instante", a saber, como aquel presente que me sale al encuentro a modo de congregación de los desplazamientos temporales extáticos del acaecer del ser. A mi modo de ver no sin razón la estudiosa equipara este presente a la noción de "situación" en Ser y tiempo: "La 'situación' -escribe- en la que se introduce el golpe de vista (Blick) pensante repensada ontohistóricamente es el presente que me sale al encuentro (Gegen-wart) del sostenido y prolongado abandono del ser" (Coriando, 1998: 104). El hecho mismo de que la exégeta vea como 
posible esta equiparación muestra la reversión de la relación entre instante y situación que se da en los Beiträge respecto de Ser y tiempo. En efecto, en 1927 el instante, concebido como la decisión del Dasein de precursar su muerte, abría la situación respectiva. Aquí, sin embargo, no es la decisión del Dasein de precursar su muerte reiterando sus posibilidades vidas lo que hace que el instante acontezca y se abra la situación, sino que el instante, concebido como el presente en el que se congregan los desplazamientos temporales de la yección del ser, es la situación misma. Para los Beiträge la experiencia (recordanteaguardante) es el presente; y el presente es el instante que nos emplaza ante o dirige hacia la posibilidad de la decisión ${ }^{15}$. Este instante identificado con una situación extática, en tanto reunión de éxtasis desplazantes, es, pues, lo que hace posible una decisión del Dasein, que ahora ya no se refiere esencialmente a sí mismo y a su modo de precursar la muerte, sino (y como condición de la autenticidad de todo precursar) al asumir un posible nuevo arribo del ser, que necesita esa asunción o proyección para poder acaecer como fundamento del ente. Hay, entonces, una reversión del orden de prioridad: no es el instante, concebido como el presente auténtico de la decisión, quien abre la situación, sino la situación, identificada con el instante y concebida como el presente que experimenta el olvido del ser, quien me coloca precisamente en situación de decidir. Las relaciones entre decisión y situación se han invertido desde el momento en que el instante ya no cae del lado de la decisión, sino del de la situación. La nueva perspectiva no es un mero cambio inmanente, sino una reversión esencial desde el punto de vista histórico y existencial. Desde el punto de vista existencial porque ahora el instante no es más el presente en que resuelvo cómo vivir y morir, sino el presente que me sale al encuentro (Gegenwart) como situación y en el cual puedo no, por cierto, resolver el efectivo

${ }^{15}$ En este sentido escribe Heidegger: "Pero este abandono del ser, en tanto originariamente recordante-aguardante (la pertenencia al ser y el llamado del ser) no es un mero hundirse y fenecer en un no tener, sino a la inversa el erigirse de un presente dirigido sólo hacia la decisión: 'instante'. En él están insertos los desplazamientos y el mismo esencia como la congregación de los desplazamientos" (1989, 384). Igualmente en el $\$ 49$ se refiere la decisión a la espacio-temporalidad surgida del abrimiento del ser mismo: "Lo espacio-temporal de la decisión ha de comprenderse como abrimiento eclosionante (aufbrechende Klüftung) del ser mismo, no en un sentido moral-antropológico" (1989: 103). Sin embargo, poco antes se afirma que es la decisión quien debe crear el espacio-tiempo, con lo cual lo espacio-temporal de la decisión parecería precisamente referirse a un sentido moral-antropológico. Escribe Heidegger: "La decisión debe crear aquel espacio-tiempo, el sitio para los instantes esenciales" (1989: 98). Pese a esta oscilación, el análisis detallado del instante en el $\$ 242$ me reafirma en la convicción de que es el presente de la experiencia del abandono del ser, identificado con el instante, quien nos coloca ante la decisión, y no a la inversa. 
acaecimiento de un nuevo arribo del ser, sino mantener abierta la posibilidad de tal arribo. Desde entonces puede decirse que no es el existente el que hace acontecer al instante como suyo, sino el instante del ser el que hace que acontezca el existente como Da-sein. Desde el punto de vista histórico porque el instante, concebido como situación, deja de ser un punto de inflexión en la historia por el cual un existente o una comunidad de existentes puede quebrar el curso de los sucesos e introducir una nueva orientación en la historia. Desde esta nueva perspectiva es la situación histórica la que se apropia del existente, cuyo rol queda reducido a estar preparado para asumir el curso que puedan tomar los sucesos a la espera de un cambio, es decir, para soportar el destino histórico. Por ello mismo el instante puede extenderse infinitamente y abarcar toda una vida o la vida de varias generaciones sin resolverse, pues el destino histórico -el nuevo arribo del ser- no puede ser producido por el instante, sino esperado por él.

Esta prioridad de la situación y la pasividad que ella implica respecto de la decisión se reafirma si consideramos no sólo el instante en su aspecto puramente temporal, sino en su integralidad como "instante-sitio". Coriando observa que, "si bien con la debida precaución para el concepto de instante la referencia a Ser y tiempo puede resultar de ayuda, falta para los conceptos correlativos de contención y de sitio -según la igual originariedad de tiempo y espacio en el pensamiento del acaecimiento- una posibilidad correspondiente" $(1998,105)$. Ciertamente para el concepto de instante abstraído del sitio sirve de referencia Ser y tiempo, pero no propiamente el concepto de "instante" de Ser y tiempo, sino el de situación, en tanto en cuanto el instante es identificado con la situación de experiencia de abandono del ser que emerge cuando se congregan en el presente los desplazamientos temporales. Esta reconducción del instante a la situación se agudiza cuando, a diferencia de Ser y tiempo, el fenómeno deja de ser pensado en términos temporales para serlo en espacio-temporales. Es entonces cuando el instante deviene "instante-sitio", concebido como aquel ámbito espacial en el que se contiene y se afinca la experiencia del olvido del ser. Ella, en tanto contenida y fijada en dicha situación espacial, se vuelve susceptible de ser soportada o resistida por largo tiempo. Justamente esta última característica del presente del abandono del ser en tanto "instante-sitio" reafirma que este último debe ser referido a un modo extático de existencia que resulta de soportar existir desplazado hacia y emplazado en aquel ámbito (sitio) en el que se vuelve presente (instante) y se deja experimentar el ser mismo como lo abandonado y olvidado. Dicho de otra manera, existir en el presente del "instante-sitio" radica en dejar que ese 
existir sea determinado por la situación (el modo de acaecer del ser) en lugar de abrir la situación por obra de la decisión que acontece en un cierto instante de resolución. Así concebido, como situación en la que me encuentro, el instante es esencialmente pasivo, porque su condición originaria es padecer como tal una cierta yección espacio-temporal del ser, a saber, como abismo. Además es responsivo, porque la existencia en el instante se desarrolla como una respuesta a esa yección consistente en recordar, en la experiencia del abandono del ser, la pertenencia al ser y, a la vez, aguardar el llamamiento a dejar que el ser acaezca. Dado su carácter pasivo y responsivo existir en el instante, reitero, no implica tomar ninguna decisión repentina que cambie el curso de mi vida o de los sucesos históricos, sino que equivale a permanecer en la situación esperando ser llamado. En este sentido puede traerse a colación la cita de Hans Erick Nossack con la que Heidegger cierra el protocolo de discusión de su conferencia "Zeit und Sein": "Se debería estar ahí [...], cuando se es llamado, empero llamar uno mismo es lo más torcido que podría hacerse" (Heidegger, 2000: 58).

Comprendido como fenómeno pasivo-responsivo la única decisión que se puede tomar en el instante es la de mantener constantemente abierto el espacio-tiempo en el que puede (o no) ocurrir una cierta posibilidad: la del arribo del ser. De allí que en los Beiträge, se lo considere "asentado" y "dado para ser soportado". De lo que se trata, pues, es de mantener abierto, recordando y aguardando, ese sitio en el que el ser se hace presente como lo olvidado. Por lo tanto el instante no le da lugar ni le concede tiempo a cualquier acontecimiento imprevisto, proveniente ya no del acaecimiento del ser en el conjunto del ente, sino de determinados entes de la realidad, que pueda conmover esa situación y sacarme del estar a la espera de ser llamado. Y ello porque vivir en el instante-sitio es precisamente soportar la situación. Queda excluido como origen del instante, entonces, el suceso singular que pudiera re-determinar mi vida, refiriéndola a él mismo y a este aquí y ahora en el que él sucede, porque el instante, identificado con experimentar la situación de abandono del ser, es una suerte de contra-presente en el que mi vida no está referida al aquí y ahora de algo que de pronto acontece -al hoy-, sino al hacerse presente del más originario pasado (la pertenencia al ser) y, junto con él, al hacerse presente el advenir de un futuro (el llamado del ser) cuya realidad efectiva sólo puedo preparar, sosteniendo constantemente su posibilidad como tal. La consecuencia de esta determinación del instante-sitio a partir de la situación es su "desinstantaneización". 


\section{Conclusión: el instante no instantáneo}

R. Rimpler considera con razón que la determinación del presente como "instante-sitio", más que a una indagación teorética sobre la naturaleza del tiempo, responde a una crítica cultural de Heidegger al sentido histórico del modo en que concibe el presente nuestra época científico-técnica ${ }^{16}$. Escribe Rimpler:

El presente criticado por Heidegger es uno completamente desgarrado, en la medida en que él, a consecuencia de su hipertrófica ansia de conocimiento y planificación, por un lado incorpora en sí pasado y futuro, pero, por otra parte, por culpa de esta incorporación, ignora como dos dimensiones fuera de su dominio tanto lo pasado por excelencia cuanto lo futuro y, por ello, los excluye de sífácticamente (2008: 24).

Rimpler afirma que la tesis de Heidegger de cara a este presente histórico desgarrado radica precisamente en tomar conciencia del desgarro que lo determina. Gracias a esta conciencia -y siempre que se la mantenga activa y vigente- "se constituye un presente, cuyo pasado y futuro, a pesar de su retracción, resultan de tal modo comprehendidos en él que ambos en su ausencia están presentes" (Rimpler, 2008: 26). Ante este planteamiento no puedo evitar formular la siguiente pregunta: ¿no siguen paradójicamente siendo absorbidos pasado y futuro en el éxtasis de este Gegen-wart heideggeriano, de modo tal que lo inesperado y ajeno continúa excluido? Me atrevería a responder positivamente. Así como el actual presente histórico excluye aquello que queda fuera de su planificación y conocimiento, "el instante-sitio" sólo da lugar a aquello que en el presente se espera que pueda ocurrir y a lo que en ese mismo presente se siente desde siempre referido. La conclusión es que en ambos casos el pasado y el futuro quedan referidos a y diluidos en el presente; ya sea aquel que lo incorpora por el cálculo y la planificación, ya aquel otro que lo congrega en virtud de su carácter extático. ¿Cuál es la consecuencia para la noción de instante de esta comprensión del presente como aquello que se extiende hacia el advenir aguardante del llamado del ser y hacia la pertenencia sida y perdurable a ese mismo ser, y que, justamente por ello, congrega futuro y pasado? Pues no otra que la inevitable extensión del instante hacia el pasado y

\footnotetext{
${ }^{16}$ Desde esa misma perspectiva, que considera la concepción del instante en los Beiträge como una crítica cultural, escribe Held: "En esta experiencia [de la retracción del ser como tal] podría abrirse la posibilidad de un comienzo fundador de historia, a través del cual fuera fundada una cultura nueva y enteramente diferente" (1991: 31).
} 
el futuro en que se cumple dicha congregación, al punto que el instante deviene un periodo extático. De hecho el "instante-sitio" no es concebido como un efectivo advenimiento del ser, pues este advenimiento es precisamente lo que se oculta en el abismo, sino como el asentarse y soportar en un sitio el presente con conciencia de pertenecer desde siempre al ser y de continuar esperando su llamado. Así visto, el fenómeno deviene un constante extenderse al pasado y al advenir y pierde su instantaneidad. Consecuentemente, en lugar de ser afirmado como la irrupción de un acontecimiento singular, imprevisible e inaugural, el fenómeno del instante deviene una suerte de "mirada situacional" que se sostiene contantemente a la espera del inicio de un proceso de cambio del sentido de las cosas y que abarca el conjunto de los horizontes temporales de la existencia. El instante, tradicionalmente comprendido como un punto de inflexión en la historia (personal o colectiva) se identifica ahora con un estado de situación, ganando en extensión lo que pierde en intensidad

Como mirada situacional el instante queda, además, inmerso en una serie de reflejos especulares entre la espacio-temporalización ex-tática de la yección (Zu-wurf) ontohistórica del ser como abismo y la espacio-temporalización, igualmente ex-tática, de la pro-yección (Entwurf) del Dasein de esa yección abisal del ser en el sentido del todo del ente. Esta inmersión del instante en tal correlación extática y especular es precisamente aquello que no puede dar cuenta del aspecto inter-ruptor del instante como acontecimiento singular, puntual, imprevisible, impreparable y alterador del devenir histórico. En efecto, dentro de la comprensión especular del "instante-sitio" ningún acaecer espacio-temporal del ser representa un "instante-sitio" histórico de cambio, si no es reflejado en la proyección que hace el Dasein de los propios horizontes espacio-temporales de su existencia; y ninguna decisión de proyectarse en la historia de un Dasein representa un instante histórico, si no refleja una yección espacio-temporal del ser. Este juego de espejos, en la que la imposibilidad de proyectar el Dasein un sentido nuevo en el todo del ente diferente del técnicoinstrumentalista no es sino el reflejo de la ausencia del acaecer del ser como fundamento; y el hasta ahora frustrado advenimiento del ser y con él de un sentido nuevo del ente no es sino el reflejo de la imposibilidad del Dasein de proyectar un modo nuevo de comprender su existencia, puede perpetuarse infinitamente, sin que ninguno de los términos de la correlación pueda por sí mismo quebrar los espejos, y sin que ningún acontecimiento singular pueda alterar esta correlación omni-abarcativa desde fuera de ella misma. Encerrado en una correlación tal, el "instante-sitio" no puede ser otra cosa que la larga espera a que ocurra el momento propicio en que los dos términos de la 
correlación se decidan al unísono a romper los espejos. El fenómeno pierde, así, su instantaneidad y deviene, en el mejor de los casos, la larga, porque consciente del pasado al que se extiende y lo incierto del futuro que aguarda, y constante, porque fijada y dada a soportar, espera de (precisamente) que ocurra un verdadero instante. La instantaneidad del instante radica, en cambio, en primer lugar, en su referencia a un acontecimiento singular que ingresa en la historia sin haber sido preparado por ella y que nos fuerza a alterar nuestra historicidad en virtud de la relación con él. Y, en segundo, en el hecho de que se concentran en el presente del acontecimiento las distintas dimensiones temporales y en él consuman su sentido, de modo que ya no se extienden hacia ningún pasado ni se proyectan ningún advenir. Desprovisto de esta referencia al acontecimiento y di-ferida la consumación de las dimensiones temporales en el ahora a una congregación de éxtasis, el instante pierde su esencia de instante y se absorbe en una situación extática desde la cual se despliegan las dimensiones temporales. Tal vez por ello, como advierte Günter Seubold, en la conferencia Zeit und Sein se deja por completo de lado la expresión "instante", "Llama la atención que no se hable más ni de instante ni de instante-sitio en tal conferencia, 'en la que debe ser despejado el tiempo en lo que tiene de propio' " (Seubold, 1989: 38). Allí donde expresamente se pregunta por la unidad de la tridimensionalidad del tiempo, pareciera que no habría nada mejor que acudir al instante para encontrarla. Empero no hallamos ni la más mínima referencia a él. Y, a mi modo de ver, no me parece que sea posible aquí acudir al expediente de comparar el término "instante" con otras expresiones adoptadas en los Beiträge y no reproducidas posteriormente en las obras publicadas por Heidegger, puesto que se trata de un término que el filósofo toma ya tempranamente de Kierkegaard y que tiene un lugar preponderante en el análisis de la temporalidad nada menos que en Sein und Zeit y en los Grundbegriffe der Metaphysik. ¿No indica, acaso, esta llamativa ausencia del término que ni el instante puede explicar la unidad o congregación extática de los modos de temporalización, ni esta unidad puede dar cuenta de lo peculiar del fenómeno del instante?

En la comprensión de los Beiträge el instante-sitio queda referido al ensamble de los éxtasis espacio-temporales y se piensa la temporalidad como extendida desde él. Ciertamente también el "instante-instantáneo", surgido del encuentro con un acontecimiento singular, im-pre-parable e im-pre-visible, hace posible la temporalidad, pues permite una renovación integral del sentido de la existencia. Sin embargo, este instante, justamente por su instantaneidad, no es la temporalidad, sino su plenitud: el acontecimiento -más o menos duradero en 
términos cronológicos- de un presente en el que se consuman mis posibilidades en consonancia y armonía con la consumación de las posibilidades de ser de todo aquello que constituye mi situación ${ }^{17}$. El instante, así concebido, es plenitud de la temporalidad no meramente porque en él se congregan las distintas dimensiones temporales, sino porque gracias a él ellas se concentran y consuman. Por eso quienes viven en el instante lo hacen "sin la prevención de la temporalidad, no sabedores del tiempo" (Kierkegaard, 2007: 42). Por eso también para ellos no hay regreso al ayer remoto de una pertenencia perdida ni espera de un incierto llamado del lejano mañana, pues, cuando el instante ocurre, ayer y mañana están presentes hoy.

\section{Bibliografía}

Coriando, Paola (1998). Der letzte Gott als Anfang. Zur abgründigen Zeit-Räumlichkeit des Übergangs in Heideggers "Beiträge zur Philosophie (Vom Ereignis)", München: Wilhelm Fink.

Drosdowski, Günther (1989). Duden Band 7. Das Herkunftswörterbuch. Etymologie der deutschen Sprache, Mannheim/ Wien/ Zürich: Dudenverlag.

Falkenhayn, Katharina (2003). Augenblick und Kairos. Zeitlichkeit im Frühwerk Martin Heideggers, Berlin: Duncker \& Humblot.

Garrido Maturano, Ángel (2010). Los tiempos del tiempo. El sentido filosófico, cosmológico y religioso del tiempo, Buenos Aires: Biblos.

Heidegger, Martin (1989). Gesamtausgabe Band 65. Beiträge zur Philosophie. (Vom Ereignis), Frankfurt a.M.: Vittorio Klostermann.

- (1993). Sein und Zeit, Tübingen: Max Niemeyer.

— (2000). Zur Sache des Denkens, Tübingen: Max Niemeyer.

Held, Klaus (1991). "Grundbestimmung und Zeitkritik bei Heidegger". Zur Philosophischen Aktualität Heideggers. Ed. Papenfuss, D. y Pöggeler, O., Frankfurt a.M.: V. Klostermann, pp. 31-55.

\footnotetext{
17 Vista desde la perspectiva del Dasein la plenitud que acontece en el instante consiste en ser de un modo tal que, por resolverme a ser de ese modo, no sólo yo realizo consumadamente mis posibilidades en este presente, sino que el conjunto de lo que es y se articula en torno mío - mi sitio o situación- puede acceder en ese mismo presente a su propia consumación. Vista desde la perspectiva del ser, podría describírsela diciendo que la plenitud radica en que el conjunto de lo que es y se articula en torno mío - mi sitio o situación- me sale al encuentro en el presente de un modo tal que no sólo lo que es consuma armónicamente las posibilidades latentes en esa situación, sino que, haciéndolo, me lleva a mí mismo a la propia consumación de mis posibilidades.
} 
KierkegaArd, Søren (2007). Los lirios del campo y las aves del cielo, Madrid: Trotta.

Rimpler, Rüdiger (2008). Prozessualität und Performativität in Heideggers "Beiträgen zur Philosophie”, Würzburg: Ergon.

Seubold, Günther (1989). "Bemerkungen zu Destruktion und Augenblick”. Destruktion und Übersetzung. Ed. Buchheim, T., Weinheim: VCH Verlagsgesellschaft.

Recibido: 4/12/2017

Aceptado: 11/01/2018

\section{(c) $(1) \Theta$}

ENDOXA está bajo una licencia de Creative Commons Reconocimiento-NoComercial-SinObraDerivada 4.0 Internacional 
